\title{
PAULO FREIRE E EDGAR MORIN: A COMPLEMENTARIDADE DE UM DIÁLOGO POSSÍVEL
}

\author{
PAULO FREIRE AND EDGAR MORIN: \\ THE COMPLEMENTARITY OF A POSSIBLE DIALOGUE
}

\author{
Karin Claudia Nin Brauer \\ Maximina Maria Freire ${ }^{* \star}$
}

\begin{abstract}
RESUMO
O presente artigo tem como objetivo estabelecer um diálogo epistemológico entre Paulo Freire e Edgar Morin, sob a perspectiva da Linguística Aplicada. Os aportes teóricos para a interlocução pretendida são a educação bancária e a emancipadora (FREIRE, 1992, 2002, 2005, 2007), a Epistemologia da Complexidade (MORIN, 1990, 1996, 2002, 2003, 2005, 2007, 2011, 2013), o entendimento de ato pedagógico (SANTOS, 2018) e a concepção de Linguística Aplicada na denominada modernidade recente (MOITA LOPES, 2006; FABRÍCIO, 2006 entre outros). A relevância dessa proposta está em levar linguistas aplicados, educadores e interessados nessas e em áreas afins a reflexões transdisciplinares que articulem a Pedagogia Crítica, a Epistemologia da Complexidade e a Linguística Aplicada.

Palavras-chave: epistemologia da complexidade; transformação; Linguística Aplicada.
\end{abstract}

\section{ABSTRACT}

The present article aims at establishing an epistemological dialogue between Paulo Freire and Edgar Morin, from the perspective of Applied Linguistics. The theoretical framework for the intended interlocution is the banking and the emancipatory education (FREIRE, 1992, 2002, 2005, 2007), the Epistemology of Complexity (MORIN, 1990, 1996, 2002, 2003, 2005, 2007, 2011, 2013), the understanding of the pedagogical act (SANTOS, 2018), and the conception of Applied Linguistics in the so- called recent modernity (MOITA LOPES, 2006, FABRÍCIO, 2006, among others). The relevance of this study is to bring applied linguists, educators and stakeholders in these and in related areas to transdisciplinar reflections that articulate Critical Pedagogy, the Epistemology of Complexity and Applied Linguistics.

Keywords: epistemology of complexity; transformation; Applied Linguistics.

\section{INTRODUÇÃO}

A transposição de barreiras epistemológicas e o anseio por um pensar e agir interdisciplinares e/ou transdisciplinares na orientação de pesquisas são traços marcantes que estão presentes nos trabalhos de muitos pesquisadores contemporâneos, dentre os quais, vários linguistas aplicados. Moita Lopes (2006), por exemplo, se posiciona a favor de uma Linguística Aplicada indisciplinar: termo propositalmente ambíguo, utilizado para ressaltar, de um lado, uma rebeldia ao estabelecimento de fronteiras rígidas, limitadoras do conhecimento e demarcadoras de áreas fixas do saber, e, de outro, termo denotador de uma percepção ampla de horizonte que se rebela ao prédeterminado e estritamente fronteiriço e simplificador. Fabrício (2006, p. 51), por sua vez, referindo-se ao que se torna distintivo no pensamento de Pennycook, Moita Lopes e Cavancanti, em relação ao tecer diferenças entre norma e desvio, advoga a existência de um "hibridismo teórico-metodológico", sinalizando uma Linguística Aplicada movente, problematizadora, crítica, preocupada com questões éticas que, como enfatizam Denzin e Lincoln (2008), está comprometida com o relacionamento entre esperanças, necessidades, promessas e objetivos de uma sociedade que se revela democrática e livre.

A postura acima descrita desenvolve-se a partir de uma visão de ciência que se embasa na concepção de que "a linguagem é ideológica e política, ou seja, é atravessada por quadros axiológicos característicos e constitutivos de determinados sujeitos e contextos sócio-históricos" (SCHEIFER, 2013, p. 920). De acordo com Pennycook (2004; 2008, p.6), mencionado por Scheifer (2013, p. 920), essa compreensão vai de encontro à noção de linguagem presente no paradigma modernista de pesquisa que, orientando-se por teorias totalizantes e universais, bem como por uma

\footnotetext{
* Instituto Federal de Educação Ciência e Tecnologia de São Paulo, IFSP, São Paulo, Brasil. kcnb76@gmail.com. Orcid: https://orcid.org/0000-0001-8581-9012

** Pontifícia Universidade Católica de São Paulo, PUC-SP, São Paulo, Brasil.mmfreire@uol.com.br. Orcid: https://orcid.org/0000-0002-7908-1143
} 
compreensão teleológica progressista e positivista do mundo, tem contribuído para a manutenção de desigualdades sociais e culturais.

Considerando as lacunas epistemológicas e investigativas ainda existentes em relação à construção de saberes inter- e transdisciplinares, o objetivo deste artigo é desenvolver um diálogo entre um educador e filósofo, Paulo Freire, e um sociólogo e filósofo, Edgar Morin, interpretando-o à luz da Linguística Aplicada'. A relevância dessa proposta está em levar linguistas aplicados, educadores ${ }^{2}$ e interessados nessas e em áreas afins, a reflexões inter- e/ou transdisciplinares que associem esses dois pensadores e articulem, principalmente, a Linguística Aplicada, a Pedagogia Crítica e a Epistemologia da Complexidade. Esse diálogo se torna especialmente pertinente em 2021, ano em que se comemora o centenário de nascimento desses dois pensadores que, apesar de contemporâneos, desenvolveram-se em espaços geográficos distintos e sob diferentes condições de vida e produção.

Tal interlocução se mostra particularmente intrigante, pois, para Morin (2011), o processo educacional compreende uma re-/co-/des-/construção recursiva contínua, não linear, não reducionista, não segmentada, que se materializa por meio da conexão de uma diversidade de saberes que se ligam e religam de várias formas, promovendo articulação entre as ciências e diálogo entre conceitos opostos, que se complementam. Freire, por sua vez, ao longo de sua obra, argumenta a favor de uma educação crítico-reflexiva que supere o modelo tradicional tecnicista, buscando maneiras de agir e pensar, a partir de um enfoque crítico-transformador que problematize, conscientize, transforme e emancipe.

A tentativa de convergência entre Freire e Morin sugere, desde o início, uma discussão pertinente, na medida em que ambos se distanciam do paradigma tradicional, enfatizando a importância da construção de saberes situados que partem do conhecimento prévio do aprendiz e de sua realidade, para se converterem em formas de pensar e em ações ecologizadas, mediadas pela linguagem, transformadoras do pensamento, do homem e da sociedade. Para tanto, é necessário conceber, como o faz a Linguística Aplicada, que a linguagem é uma prática social e que práticas discursivas não são neutras, uma vez que abarcam escolhas lexicais, sempre ideológicas e políticas, reveladoras de alguma relação de poder que podem provocar diferentes efeitos no mundo social. Além disso, é preciso reconhecer que o processo de elaboração de sentidos considera uma multiplicidade de sistemas semióticos, levando a Linguística Aplicada, em um movimento recursivo, às suas bases epistemológicas, conhecido como "virada crítica", "virada icônica" ou "virada linguística e cultural" (cf. FABRÍCIO, 2006, p. 48-49).

Para atingir o objetivo proposto neste artigo e trazer contribuições às áreas nele contempladas, delineamos o diálogo epistemológico proposto, apresentando primeiramente o pensamento de Freire, para depois detalhar o de Morin. Intencionalmente, optamos por fazer uma exposição de cada autor separadamente para, então, aproximandoos e/ou distanciando-os, evidenciar que paralelo podemos traçar entre tais interlocutores.

\section{PAULO FREIRE: DE UMA VISÃO BANCÁRIA A UMA VISÃO EMANCIPADORA}

Pensar que a esperança sozinha transforma o mundo e atuar movido por tal ingenuidade é um modo excelente de tombar na desesperança, no pessimismo, no fatalismo. Mas, prescindir da esperança na luta para melhorar o mundo, como se a luta se pudesse reduzir a atos calculados apenas, à pura cientificidade, é frívola ilusão. Prescindir da esperança que se funda também na verdade como na qualidade ética da luta é negar a ela um dos seus suportes fundamentais. A essência, como digo [mais adiante] no corpo d[est] a Pedagogia da esperança, é que ela, enquanto necessidade ontológica, precisa de ancorar-se na prática. Enquanto necessidade ontológica, a esperança precisa da prática para tornar-se concretude histórica. E por isso que não há esperança na pura espera, nem tampouco se alcança o que se espera na espera pura, que vira, assim, espera vã (FREIRE, 1992, p.5).

Opressão, liberdade, autonomia e esperança são termos - ou melhor, construtos genuínos - que, de certa forma antagônicos, marcam e identificam a obra de Freire de modo definitivo. Ao longo de sua carreira, o autor faz de seus livros e atitudes instrumentos de denúncia e defesa de justiça social, comprometida com a transformação e emancipação humanas. Em grande parte de suas obras, a temática central é "a sociedade excludente, desumana e desumanizadora na qual nasceu, viveu, interagiu com outros seres humanos, lutou, sofreu e foi reprimido e exilado"

1. Ressaltamos que propostas de articulação entre Freire e Morin já têm sido apresentadas na área de Educação por Malachias \& Silva (2012) e Scholze \& Scholze (2014), por exemplo. No entanto, no âmbito da Linguística Aplicada, o diálogo pretendido neste artigo mantém um caráter de ineditismo.

2. Neste artigo, os termos educador, professor e docente são utilizados como sinônimos, sem nenhuma conotação diferenciadora. Intenção semelhante é atribuída aos termos educando, estudante, aprendiz e aluno. 
(SANTOS, 2018). Em outras (FREIRE, 1992, 2002, 2005, 2007), contudo, ressalta a esperança de um mundo livre, enfatizando o homem como ser consciente da realidade. A humanização e a recuperação histórica da liberdade se tornam indicações marcantes da produção. A partir de tal caracterização, a educação, na perspectiva do autor, é entendida como o meio que auxilia a desenvolver a consciência crítica do homem para, assim, transformá-lo e libertálo.

Freire $(1992,2002,2005,2007)$ tem na educação popular uma atividade não apenas pedagógica, mas também política que visa a fortalecer a consciência da cidadania e liberdade, por meio da reflexão/autorreflexão sobre a história, a própria história. De acordo com o educador, há necessidade de se colocar em prática o procedimento pedagógico da ação-reflexão-ação, tendo em vista a possibilidade de distanciar-se da educação impositiva do saber do dominante sobre o do dominado. Segundo o autor, o desenvolvimento da consciência crítica em relação à história, ao mundo e a si mesmo é condição para que o ser humano alcance a autonomia. Nesse sentido, Freire (2002 p. 66) enfatiza que "o respeito à autonomia e à dignidade de cada um é um imperativo ético e não um favor que podemos ou não conceder uns aos outros".

Um dos destaques marcantes da pedagogia freiriana é sua oposição ao paradigma newtoniano-cartesiano, ou tradicional, conteudista, distinguido pelo entendimento do professor como sujeito ativo, detentor do saber a ser transmitido para o aprendiz, entendido como receptor passivo, vazio desses saberes fragmentados e descontextualizados, e incapaz de construí-los sem a ajuda docente. Essa é a caracterização que Freire (2002) confere à "educação bancária": um ato de depositar, de transferir saberes e valores sem uma conduta crítica, sem relevância sociocultural. A respeito desse conceito, o autor (FREIRE, 2005, p.33) explicita:

Em lugar de comunicar-se, o educador faz "comunicados e depósitos aos educandos, meras incidências, recebem pacientemente, memorizam e repetem. Eis a concepção "bancária" de educação, em que a única margem de ação que se oferece aos educandos é a de receberem os depósitos, guardá-los e arquivá-los. Margem para serem colecionadores ou fichadores das coisas que arquivam. No fundo, porém, os grandes arquivados são os homens, nesta (ou na melhor das hipóteses) equivocada concepção "bancária" da educação. (...) Na visão "bancária" da educação, o "saber" é uma doação dos que se julgam sábios aos que julgam nada saber (grifos do autor).

$\mathrm{Na}$ relação existente entre professor e aluno na educação bancária, o destaque do processo educativo está na maneira de transmitir os conteúdos antecipadamente selecionados. A atividade pedagógica se reduz aos métodos de transmissão, a tudo o que possa auxiliar a fixação, a memorização. Nessa perspectiva, professor competente é aquele que apresenta um conjunto de dinâmicas que facilitem o entendimento, a repetição e a retenção dos conteúdos. $\mathrm{O}$ monólogo por parte do professor é característica marcante desse processo.

Em contrapartida à educação bancária, Freire (2002) propõe a educação emancipadora, um compromisso político, que tem como pressuposto a luta contra a opressão e dominação. Para o autor (FREIRE, 2002, p. 16), esse conceito de educação emerge como condicionamento ético, denominado "ética universal do ser humano". Tal questão ética materializa-se na consolidação de uma educação libertadora, proporcionando condições para estudantes e educadores se considerarem sujeitos de sua própria história e de construírem uma sociedade justa, igualitária, libertando-se, desse modo, das formas de opressão e exclusão sociais.

Freire defende uma educação na qual professores e alunos, "ambos críticos", sejam "sujeitos da ação pedagógica" (SANTOS, 2018), por meio de ações e contextos problematizadores em que o docente possa exercitar o pensar crítico e na qual ocorra o "verdadeiro diálogo" (SANTOS, 2018), ou seja, uma relação educativa intersubjetiva entre sujeitos que ensinam e aprendem em conjunto, "mediatizados pelo mundo" (FREIRE, 2005, p.39). Segundo o autor, apenas uma educação problematizadora e dialógica pode garantir uma educação emancipadora, uma educação como ato pedagógico, assegurando o desenvolvimento de uma consciência crítica e transformadora da realidade (SANTOS, 2018). Enquanto a concepção bancária nega a dialogicidade como essência da educação e se faz antidialógica; a educação problematizadora - situação gnosiológica - afirma a dialogicidade e se faz dialógica (FREIRE, 2005, p. 39).

O diálogo tem como característica a união entre pessoas com um evidente interesse comum de procura, um compartilhamento de objetivos que conduz à interação genuína. Conforme Carvalho (2005, p. 69), "o diálogo é a fonte geradora de reflexão, e o encontro com o outro é a primeira condição da instauração do diálogo em sala de aula [...]". Partindo dessa definição, é importante considerar que a ligação dialógica mantida entre professor e alunos, na linha da educação libertadora de Freire (2002), tem como meta a emancipação humana, a autonomia. Esse objetivo é

3. A citação aqui feita não inclui referência à página, pois foi consultada a edição Kindle dessa obra a qual, dependendo da fonte escolhida, pode provocar variação na paginação, em confronto com o original impresso. 
que torna a ligação professor-aluno uma relação de companheirismo. Somente com a dimensão do amor pelo mundo e pelo próprio ser humano é possível proporcionar o diálogo educativo que assume uma característica dinâmica, pois se torna uma forma de reflexão ativa que evoca a criatividade e o compartilhamento de experiências.

Freire (2002, p. 14) argumenta "sobre a prática educativo-progressista em favor da autonomia do ser educando", porém esclarece que essa prática só se viabiliza com uma formação docente que seja coerente com seus pressupostos. Para Freire (2002), a prática docente exige: rigor metódico, pesquisa, respeito aos saberes dos educandos, criticidade, ética e estética, corporificação de palavras pelo exemplo, reflexão crítica sobre a prática, reconhecimento e assunção da identidade cultural, conscientização do inacabamento, respeito à autonomia do ser educando, bom senso, humildade, tolerância, convicção de que mudar é possível, curiosidade e competência profissional.

A postura teórica a respeito das exigências da prática docente de Freire é compreendida quando se analisam suas concepções e princípios educacionais, expressos em práxis educativa. A formação docente e os princípios da educação libertadora, emancipadora são partes interligadas a todo fenômeno educativo. Desse modo, para ter clareza sobre os pressupostos da educação emancipadora faz-se necessário entender a proposta da formação docente que é construída sobre a base da ação reflexiva e dialógica e se profere como probabilidade de transformação da pessoa e da sociedade.

Entre os diferentes estados de consciência que Freire (2002, p.40) apresenta, destaque especial é dado à consciência crítica, caracterizada por uma visão questionadora que tem como proposta investigar os problemas de maneira profunda. Freire $(2002$, p. 33) ressalta que a consciência crítica possibilita ao ser humano transformar a realidade e, por meio dela, o docente pode compreender melhor o contexto em que se encontra, ultrapassando limites - os limites da sala de aula, por exemplo.

É relevante destacar que as questões críticas abordadas por Freire, em sua obra, encontram embasamento na Pedagogia Crítica (1970) que propõe, a qual parte da premissa de que a formação crítica deve conduzir ao desenvolvimento de cidadãos capazes de analisar suas realidades social, histórica e cultural, criando oportunidades para transformá-las, conduzindo alunos e professores a uma maior autonomia e emancipação. De acordo com Freire (2005), essas transformações não poderiam permanecer no campo das ilusões ou abstrações, pois o professor crítico - e reflexivo - tem como uma de suas características a preocupação com as consequências éticas e morais de suas ações na prática social. Freire (2005) também ressalta que um educador transformador crítico insere a escolarização diretamente no campo político e vice-versa. Desse modo, concebe os alunos como agentes críticos; o diálogo também se evidencia crítico; o conhecimento se torna problematizador, e os argumentos se direcionam em busca de um mundo melhor.

Refletindo sobre o pensamento de Freire (2005), compreendemos que o educador crítico considera a voz e a participação ativas dos alunos, cujos sentidos e significados de ser e estar no mundo, construídos historicamente, permeiam todas as suas ações no que diz respeito à aprendizagem, à escola e à sociedade. A utilização de uma linguagem crítica, como orientadora do processo reflexivo, torna-se relevante para a formação de professores e alunos, conscientes do seu agir na sociedade e de seu papel no mundo. Dessa forma, as ações de linguagem geradas por seus discursos não se embasam em conteúdos programáticos, somente; mas surgem de um processo reflexivo que parte de ações mais amplas, estreitamente vinculadas à realidade que se vive. Em outras palavras, a linguagem pode mediar o pensamento do professor sobre suas práticas educativas, ao mesmo tempo em que é usada como objeto de suas ações dentro e fora da sala de aula.

\section{MORIN: DO PARADIGMA TRADICIONAL A UMA REFORMA DO PENSAMENTO}

Na medida em que são mal percebidas, subvalorizadas, separadas umas das outras, todas as crises da humanidade planetária são, ao mesmo tempo, crises cognitivas. Do modo como nos foi inculcado, do modo como foi impregnado na mente, nosso sistema de conhecimento conduz a importantes erros no autoconhecimento. Nosso modo de conhecimento subdesenvolveu a aptidão de contextualizar a informação e integrá-la em um conjunto que lhe dê sentido. Submersos na superabundância de informações, para nós, fica cada vez mais difícil contextualizá-las, organizá-las, compreendê-las. A fragmentação e a compartimentalização do conhecimento em disciplinas não comunicantes tornam inapta a capacidade de perceber e conceber os problemas fundamentais e globais. A hiperespecialização rompe o tecido complexo do real, o primado do quantificável oculta a realidade afetiva dos seres humanos. Nosso modo de conhecimento fragmentado produz ignorâncias globais. Nosso modo de pensamento mutilado conduz a ações mutilantes. [...] A reforma do conhecimento exige a reforma do pensamento (MORIN, 2013, p.183-184). 
Conbecimento, crise, pensamento complexo, reforma, imprevisibilidade, incerteza, contradição e os princípios sistêmico, recursivo, dialógico e bologramático são alguns dos construtos que definem a Epistemologia da Complexidade, como entendida e propagada por Morin, no conjunto de sua obra, ao longo de sua vida praticamente centenária. Suas obras articulam, de forma consistente, saberes de diversas áreas do conhecimento, num exercício autêntico, meticuloso e incansável de transdisciplinaridade, que transforma o autor em um tecelão epistemológico, que vai escolhendo e urdindo fios de texturas e matizes semelhantes e distintos, para compor tramas inéditas de padrões e coloridos sensíveis e legítimos; diferenciados, às vezes, mas, nesses casos, de caráter complementar.

A visão moriniana concebe a existência de uma trindade complexa, composta por indivíduo, espécie e sociedade que constitui o ser humano; e de um tetragrama da complexidade (MORIN, 2005, p. 204), formado por ordem, desordem, interação e organização, que reifica a complexidade. A articulação entre esses conceitos é de fundamental importância para o entendimento do pensamento complexo, pois evidencia que o ser humano se constitui da/na emergência entre as relações da trindade complexa (i.e., entre o indivíduo, a espécie e a sociedade), e se desenvolve alternando polos no tetragrama da complexidade, de acordo com a direção da interação, ou seja, alternando ordem e desordem, pelo movimento da interação, alcançando sempre uma nova forma de organização.

Para Morin (2011), a necessidade de se reformar o pensamento é imperativa e urgente: é preciso rejeitar o pensar tradicional, linear, reducionista e simplificador, incapaz de fornecer respostas condizentes com a realidade contemporânea. Nesse sentido, o pensamento complexo, ao contrário do tradicional, característico do paradigma newtoniano-cartesiano, considera as ambiguidades, contradições, incertezas, imprevisibilidades, indeterminações e incompletude como aspectos constituintes da vida, valorizando o ato de ensinar a compreensão humana que abarque tais características. O pensamento complexo, não linear e não fragmentador, procura estabelecer uma articulação entre os mundos físico, mental e espiritual, realçando a auto-eco-organização; ligando, religando e construindo os saberes da organização do universo exterior, inscrita no interior de nossa própria organização vivente. Por isso, para Morin (2003, p.89), é necessário suprir

um pensamento que isola e separa por um pensamento que distingue e une. É preciso substituir um pensamento disjuntivo e redutor por um pensamento do complexo, no sentido originário do termo complexus: o que é tecido junto.

Para Morin (1990, 1996, 2002, 2003, 2005, 2007, 2011, 2013), o olhar complexo cria uma ótica paradigmática, evoluindo da visão newtoniano-cartesiana para uma visão complexa, relacional, tecida junto. Esse olhar inédito evidencia a interdependência de saberes da qual emerge uma concepção original de conhecimento: um conhecimento hologramático, em que as partes, interconectadas e interdependentes, estão no todo e o todo está nas partes; um conhecimento incompleto, inacabado, em constante devir, como em um sistema aberto; um conhecimento marcado por uma causalidade circular em que uma causa não resulta sempre no mesmo efeito, pois o efeito pode retroagir à causa; um conhecimento em que a diferença não indica contradição, mas pode revelar complementaridade. Trata-se do conhecimento e do pensamento em rede, relacional, tecido rizomaticamente, e ininterruptamente em processo de construção, não atingindo uma síntese finalizadora e conclusiva. Essa busca pela não síntese se expressa pelo princípio dialógico, típico do tratamento complexo dado aos conceitos opostos, complementares. Referindo-se a Morin, Santos (2018) afirma:

Morin não vê [ess] a possibilidade de sínteses definitivas e, sim, a dura realidade da convivência dos contrários como que a sustentar o movimento da vida, o movimento da História e o movimento do pensamento, movimento de certa forma inacabável.

Sobre essa questão, Morin (2011, p.86) explica:

Creio que a propriedade de muitas coisas vivas, organizadas, é que elas vivem de contradições sem poder ultrapassá-las; o viver é, de alguma maneira, superá-las, mas sem que aí haja o além (do outro lado) da contradição.

Ressaltar a necessidade e iminência de uma reforma do pensamento e do conhecimento significa enfatizar a urgência de uma reforma da educação para trazer à tona "uma imensa dificuldade", destacada por Morin (2013, p.191) e, quem sabe, tentar equacioná-la de alguma forma: "não se pode reformar a instituição sem antes reformar as mentes, mas não se pode reformar as mentes sem antes reformar as instituições".

Inegavelmente, estamos diante dessa contradição, procurando resolvê-la em alguma medida pois, se encontramos docentes e gestores desaminados e desencantados com o atual cenário educacional, ainda temos "boas vontades latentes para a solidariedade" e, certamente, ainda "existe no corpo docente uma vocação missionária 
latente" (MORIN, 2013, p.191). Em oposição a Morin, no entanto, acreditamos que a questão não seja missionária, mas reflexiva e agentiva, como o próprio autor esclarece: "devemos aprender a pensar, tarefa de salvação pública que começa por si mesma" (MORIN, 2013, p.191). Esse desafio pode parecer hercúleo, inicialmente, mas entendemos que poderá ser minimizado à medida que nos dispusermos a enfrentá-lo.

Segundo Morin (2013, p.192-198), a reforma da educação deve partir do "ajudar a aprender a viver". O autor faz esse destaque com base na obra Emílio, de Jean-Jacques Rousseau, enfatizando que se aprende a viver com as próprias experiências, com a ajuda do outro (pais e professores, em especial), bem como dos livros e da poesia. Nesse sentido, o autor insiste que é preciso ligar os saberes das várias disciplinas para alcançar uma forma mais complexa de conhecer, de pensar. Para Morin (2013, p.192-193),

Enquanto não religamos os conhecimentos segundo o conhecimento complexo, permaneceremos incapazes de conhecer o tecido comum das coisas: não enxergaremos senão os fios separados de uma tapeçaria. Identificar os fios individualmente jamais permite que se conheça o desenho integral da tapeçaria.

A citação anterior sugere que articular saberes de várias disciplinas pode favorecer a capacidade de pensar os problemas individuais e coletivos em sua complexidade, permitindo lidar com ambiguidades e ambivalências, além de ensinar a associação de termos antagônicos e o posicionamento de qualquer informação em seu contexto, ou seja, na ecologia do sistema do qual faz parte.

Segundo Morin (2013, p.193), a reforma da educação também prevê o ensino das diversas formas de racionalidade (teórica, crítica, autocrítica), das perversões da racionalidade (racionalização, razão instrumental), da necessidade da razão aberta (sobre os dados que contradizem e sobre a crítica exterior). Além disso, uma reforma educacional ensinaria que a ecologia da ação, a partir de sua aplicação, revelaria que a "ação submete-se às interretroações do meio no qual intervém, escapa à vontade de seu iniciador e pode ir em sentido contrário ao da intenção no momento inicial" (MORIN, 2013, p.194). Finalmente, a reforma da educação abordaria os problemas essenciais, globais e fundamentais, ocultados pela fragmentação das disciplinas.

Como citado anteriormente, a reforma da educação está associada a uma contradição, uma vez que, paradoxalmente, ela exige uma reforma do pensamento: "são duas reformas pedagógicas em circuito recursivo, uma produtora/produto da reforma da outra" (MORIN, 2013, p. 201). Contudo, o próprio autor (MORIN, 2013, p.201) sugere um caminho:

Na verdade, será por meio da multiplicação de experiências-piloto que poderá nascer a reforma da educação, reforma particularmente difícil de introduzir, pois nenhuma lei seria suficiente para implantá-la. Será ela, no entanto, que conduzirá à criação de um tipo de mente capaz de enfrentar os problemas fundamentais e globais e de religá-los ao concreto.

Discutida a questão da reforma do pensamento e da educação, torna-se necessário destacar o objetivo da educação que, de acordo com Morin (2011), é formar o cidadão do/no/para o mundo, o cidadão planetário, que se percebe uno e múltiplo ao mesmo tempo; que liga e interliga a parte ao todo e o todo à parte; que une a singularidade do universo e a multiplicidade dos saberes que articula e dos conhecimentos que liga e religa continuamente. Esse cidadão é o que, reformando seu pensamento e sua forma de construir conhecimentos, irá se transformar, reconhecendo-se sistêmico, recursivo, dialógico, hologramático e, portanto, complexo. Reconhecer-se um cidadão complexo, planetário, oportuniza conscientização, autonomia/dependência, transformação. Contudo, nos parece que tais características são conquistas primeiramente percebidas no nível da tríade corpo-mente-espírito para, posteriormente, tornarem-se uma conquista percebida no nível de uma tríade mais abrangente: individuo-espécie-sociedade. Entendemos que a conscientização e a transformação conquistadas por meio da reforma do pensamento - que se processa por uma via que contempla o individual e o planetário simultaneamente - sejam, de fato, aspectos significativos da visão moriniana que envolvam perspectivas éticas, ideológicas e políticas, tratadas de forma subliminar ao longo de sua obra.

Essa percepção pode ser ilustrada pela apresentação dos sete saberes necessários à educação do futuro (MORIN, 2002, 2011) - ou melhor, do agora presente - que, consequentemente, se refletem no processo de formação docente e, por extensão, do cidadão planetário. Para o autor, os saberes são:

i. o erro e a ilusão, referindo-se aos riscos de erro e ilusão em qualquer conhecimento;

ii. o conbecimento pertinente, correspondente à importância de se apreender as relações e influências recíprocas entre as partes e o todo, assumindo, assim, os princípios de um conhecimento situado em seu contexto e no conjunto ao qual está vinculado; 
iii. ensinar a condição bumana, significando o ato de respeitar e valorizar a complexidade humana;

iv. ensinar a identidade terrena, enfatizando a necessidade de refletir sobre a crise planetária característica do século $\mathrm{XX}_{\text {; }}$

v. enfrentar as incertezas, refletindo a necessidade de conviver com um mundo imprevisível,

vi. ensinar a compreensão, objetivando desenvolver a compreensão mútua; e

vii. a ética do gênero bumano, correspondendo ao ato de conceber a humanidade como comunidade planetária, composta de pessoas que vivem em democracia.

Aprofundando o âmbito da formação docente e associando-o à visão complexa, Moraes (2007) afirma ser necessário um esforço coordenado, sistemático e simultâneo que articule várias características. Dentre elas, carecemos de uma proposta competente de reforma curricular da formação de professores que considere o tempo e a disponibilidade dos interessados, a possibilidade de um diálogo mais competente entre Estado, sociedade e as organizações docentes, bem como novas bases teóricas relacionadas aos novos paradigmas da ciência. Tornase relevante verificar que a escola do século XXI precisa de docentes que não se enquadrem no perfil de meros transmissores de conhecimentos, típicos do paradigma tradicional, newtoniano-cartesiano. Faz-se necessário desenvolver mais projetos que oportunizem aos professores condições para que seus estudantes identifiquem problemas a partir de análises, discussões, sendo possível estabelecer relações com os fatos, trabalhando de maneira a fazer descobertas a partir de suas próprias observações.

\title{
3. FREIRE E MORIN SOB A TESSITURA DA LINGUÍSTICA APLICADA
}

\begin{abstract}
Vivemos tempos de grande ebulição sócio-cultural-político-histórica e epistemológica que muitos chamam de pós modernos (VENN 2000), de modernidade recente (CHOULIARAKI \& FAIRCLOGH, 1999), de modernidade reflexiva (GIDDENS, BECK \& LASH 1997) etc., caracterizados por desenvolvimentos tecnológicos que afetam o modo como vivemos e pensamos nossas vidas tanto na esfera privada quanto na pública. São tempos em que os ideais da modernidade têm sido questionados e reescritos, principalmente aqueles referentes à definição do sujeito social como homogêneo, trazendo à tona seus atravessamentos identitários, construídos no discurso (MOITA LOPES, 2002), como também os ideais que dizem respeito a formas de produzir conhecimento sobre tal sujeito, que tradicionalmente o descorporificavam no interesse de apagar sua história, sua classe social, seu gênero, seu desejo sexual, sua raça, sua etnia etc. (...) É assim que a LA [Linguística Aplicada] precisa dialogar com teorias que têm levado a uma profunda reconsideração dos modos de produzir conhecimento em ciências sociais (cf. SIGNORINI, 1998b), na tentativa de compreender nossos tempos e de abrir espaço para visões alternativas ou para ouvir outras vozes que possam revigorar nossa vida social ou vê-la compreendida por outras histórias. Isso parece ser imperioso em uma área aplicada que, em última análise, quer intervir na ou falar à prática social (MOITA LOPES, 2006, p. 22-23)
\end{abstract}

Após intencionalmente detalharmos, de forma individual, os autores escolhidos para a interlocução-alvo neste artigo, passamos a articular os pensamentos de Paulo Freire e de Edgar Morin, interpretando-os à luz da Línguística Aplicada. Nossa opção pela Linguística Aplicada se justifica, em primeiro lugar, por ser essa a nossa área de formação e atuação, mas, principalmente, porque ela, como destaca Celani $(2017$, p.9) - que se iniciou como aplicação da Linguística e encontrou certa independência quando começou a ser associada ao ensino de línguas (particularmente ao ensino de língua inglesa) - , tem se firmado como campo do saber transdisciplinar. Suas fronteiras são moventes e flexíveis, sendo identificada na modernidade recente de forma bastante apropriada ao seu papel e movimento: INdisciplinar (MOITA LOPES, 2006). Como Celani (2017, p. 10) especifica, a Linguística Aplicada busca, em outros domínios, interação dinâmica para encontrar "esferas de coabitação" (PORTELLA, 1993), envolvendo "uma problemática transversal, através e além". Neste artigo, lançamos mão de sua marca INdisciplinar e de seu caráter mestiço (cf. MOITA LOPES, 2006), percorrendo suas esferas de coabitação e fronteiras moventes, para estabelecer conexões e desvios entre Freire e Morin.

Partimos do diálogo, como aspecto de aproximação/distanciamento entre os autores. Como apontado por Santos (2018), Freire concebe o diálogo como o "encontro amoroso entre os homens mediatizados pelo mundo". Trata-se do caminho de ajuda mútua da humanização do homem e da humanização do mundo; transcende a conversa para situar-se na reflexão, a reflexão que permite a libertação do oprimido. Para Morin, o diálogo "indica a consciência crítica dos contrários presentes nas relações. Não é comunhão passiva e, sim, ativamente provocadora de ações de transformação" (SANTOS, 2018).

Refletindo sobre tais considerações, observarmos que os autores percebem o diálogo como um ponto de encontro, de convergência, que não significa consenso entre eles, necessariamente; é um ponto de encontro para exposição 
do en e de ideias, de humanização, de transformação, de contato com opostos que se complementam. A partir de Freire e Morin, concebemos o diálogo como espaço relevante para construção, desconstrução, reconstrução, coconstrução de ideias e conhecimentos, mediados pela linguagem, pelo outro e pelo meio. O diálogo é prática social situada que envolve construção, negociação e intercâmbio, promovendo crescimento, formação, autonomia e, potencialmente, transformação (do homem e do conhecimento). O diálogo envolve reflexão, que pode ser entendida como a autorreflexão-histórica, sobre a qual versa Freire $(1992,2002,2005,2007)$ e a autoformação, defendida por Morin $(1990,2011)$ - ambos os tipos de reflexão buscam a questão sociológica do sujeito/cidadão, seja para fazer a religação sociológica e desenvolver o sujeito planetário (MORIN, 1990, 2011), ou para a busca da autonomia e liberdade sociológica, desenvolvendo o sujeito liberto, emancipado (FREIRE, 2002, 2005, 2007).

Abordando a questão do diálogo e buscando aproximar Freire e Morin, Santos (2018) argumenta:

Ambos percebem que o diálogo possibilita o conhecimento autêntico que se constitui nas interações humanas (Freire), facilitando, também, o conhecimento pertinente (Morin) e que o ato educativo deve contribuir para uma vida mais digna e autônoma.

Daí a necessidade, para ambos, de uma nova educação que privilegie o diálogo (Freire) e que desenvolva uma nova maneira de pensar, que é o pensamento complexo (Morin). Para ambos não cabe à educação escolar buscar "encher" as cabeças ou as mentes de conteúdos não compreendidos: veja-se a ideia de educação bancária de Freire e a ideia de cabeça bem-feita oposta à ideia de cabeça cheia que Morin busca em Montaigne (grifo do autor).

Persistindo na significação do diálogo para os autores em questão, também podemos destacar que, por um lado, Freire $(1992,2002,2005,2007)$ apresenta a educação como prática da liberdade e o diálogo como traço fundamental para a emancipação da sociedade; por outro lado, Morin $(1990,2011)$ cita a necessidade de um pensamento dialógico e multidimensional, com saberes não fragmentados, envolvendo sistemas abertos que permitem a ligação de conceitos opostos complementares. Nesse sentido, a abordagem que revelam em relação ao conceito se distancia, contrariamente ao que foi exposto anteriormente. Esse movimento de aproximação e distanciamento indica que o conceito não pode ser avaliado como totalmente compatível para os dois autores, apesar de apresentar significativos pontos de toque.

Em relação à visão que os autores apresentam sobre educação, temos considerações interessantes que partem de um ponto comum - as restrições e divergência de ambos quanto ao paradigma educacional tradicional e à construção de conhecimentos fragmentada e linear - para manifestações que se direcionam a caminhos epistemológicos distintos. Freire (2005, p. 65) defende uma educação para a liberdade e argumenta sobre as diferenças epistemológicas entre o que denominou "concepção bancária da educação" (ou seja, a concepção tradicional) e "educação transformadora" (sua proposta). A visão de educação freiriana visa partir do conhecimento prévio do aprendiz para, à medida que contextualiza conteúdos, desenvolver-lhe o senso crítico e transformá-lo, promovendo sua autonomia e emancipação. A educação é algo intrinsecamente encravado na realidade que se faz no jogo das contradições. Seu cerne é o indivíduo e seu contexto, a realidade em que vive.

Morin (2003, p.65), em um sentido amplo, defende uma educação que contribua para a autoformação da pessoa, ensinando-a a assumir a condição humana, a viver e a tornar-se um cidadão. Para ele, um cidadão se define por sua "solidariedade e responsabilidade em relação a sua pátria", o que supõe o "enraizamento de sua identidade nacional". A consciência e o sentimento de pertencimento à Terra, bem como a identidade terrena são vitais para Morin (2003, p.73). Segundo o autor (MORIN, 2003, p. 74),

precisamos também estender a noção de cidadania a entidades que ainda não dispõem de instituições prontas - como a Europa, para um europeu -, ou não dispõem absolutamente de instituições políticas comuns, como o planeta Terra. Uma tal formação deve permitir enraizar, dentro de si, a identidade nacional, a identidade continental e a identidade planetária.

Contrastando as visões apresentadas, constatamos que Morin apresenta uma perspectiva educacional de repercussão mais abrangente do que Freire, na medida em que procura formar o cidadão planetário: sua noção de contextualização é mais compreensiva do que a freiriana que situa o indivíduo em um limite comparativamente mais restrito, ou seja, circunscrito à sociedade em que vive e aos contextos em que atua. Nesse sentido, Morin nos parece mais audacioso ao ultrapassar as fronteiras locais para ecologizar-se no domínio terreno, planetário. Seu cerne, então, é o cidadão e o planeta em que vive.

Aprofundando nossa argumentação sobre a questão educacional, destacamos que a educação bancária, criticada por Freire (2005, p.36), possibilita aos estudantes estarem "no mundo e não com o mundo e com os outros". Para o 
autor, sob esse enfoque educacional, os aprendizes seriam espectadores e não transformadores do mundo. A educação bancária idealiza a consciência como algo específico, especializado, não percebendo os seres humanos como corpos conscientes: é como se a consciência fosse um departamento dentro do homem para ser preenchido com a realidade.

Freire $(1992,2002,2005,2007)$ também critica educadores que acreditam que o professor deva manter o controle, ser o portador dos conhecimentos a serem transmitidos, desenvolvendo práticas centradas em si mesmo, como: repetição, exposição de conteúdos, cópia e memorização - características do paradigma tradicional. Seu julgamento se justifica pelo fato de que tais ações não permitem uma relação de interação genuína entre professor e aprendizes, de ênfase aos contextos, de significação e construção compartilhada do conhecimento. Essas considerações nos remetem a uma reflexão sobre a necessidade de considerar a interação, bem como a produção e articulação de saberes, compreendendo-lhes os significados.

Morin $(2003,2013)$ também se posiciona contrariamente ao educador controlador, dono do saber, pois compreende a construção de conhecimento como processo colaborativo, de tessitura partilhada entre professor e alunos. Para o autor, trata-se de um processo recursivo que tem início a partir do contato com a nova informação que, intuitivamente, procura se conectar com o conhecimento prévio, armazenado, em busca de alguma referência em que possa se ancorar, com que possa se relacionar. Havendo essa possibilidade, é estabelecido um circuito recursivo hermenêutico, de idas e vindas, que permite a articulação rizomática entre as novas informações e os conhecimentos já existentes, expandindo-os, em rede, para várias direções. Esse entendimento sobre o processo de construção de conhecimento, em contraste com a perspectiva dominante no paradigma tradicional, conduz o autor a clamar, categoricamente, pela necessidade de uma reforma do pensamento que atenda às necessidades de um mundo em mudança, uma reforma que não perpetue a visão polar ${ }^{4}$, reducionista, simplificadora, fragmentadora, que tem caracterizado o paradigma newtoniano-cartesiano.

A aproximação/distanciamento entre Freire e Morin que nos propusemos delinear é uma tarefa que, de fato, demandaria dimensões bem maiores do que a pretendida neste artigo no qual, por uma questão de espaço, limitamonos a comentar, apenas, alguns aspectos que nos pareceram mais relevantes para um estudo introdutório sobre o assunto. Entretanto, ainda que com tal restrição, não poderíamos deixar de abordar a questão da criticidade.

Freire é conhecido nacional e internacionalmente como o criador da Pedagogia Crítica. De acordo com o Dicionário Paulo Freire (MOREIRA, 2016, p.97):

A criticidade, para Freire, é a capacidade do educando e do educador refletirem criticamente a realidade na qual estão inseridos, possibilitando a constatação, o conhecimento e a intervenção para transformá-la. Essa capacidade exige um rigor metodológico que combine o "saber da pura experiência" com o "conhecimento organizado", mais sistematizado. O seu principal objetivo é fazer com que as pessoas e as classes oprimidas, que aceitam esse desafio, possam pensar certo e se constituírem como sujeitos históricos e sociais, que pensam, criticam, opinam, têm sonhos, se comunicam e_dão_sugestões (FREIRE, 1997, grifos do autor).

Nessa perspectiva, o educador deve desempenhar a posição de sujeito e, não, de simples objeto de sua história, defendendo, de forma coerente, um processo de libertação que favoreça a vocação ontológica do ser humano de ser mais (MOREIRA, 2016, p.97). O educador crítico deve refletir e aperfeiçoar, constantemente, a prática educativa por meio de um diálogo, "intenso e aberto" com os educandos e uma "análise crítica da própria realidade", em favor da autonomia deles e da sua própria (MOREIRA, 2016, p.98). O desenvolvimento desse processo de reflexão crítica permitirá que passe da curiosidade ingênua para a curiosidade epistemológica, buscando formar "pessoas críticas, de raciocínio rápido, com sentido de risco, curiosas, indagadoras" (FREIRE, 2002, p.100). Como destaca Moreira (2016, p.98):

A ação transformadora da realidade, enquanto um exercício da criticidade em direção à práxis política, constitui-se a partir de práticas educativas que despertam a curiosidade epistemológica dos educandos e contribuem para a construção de um novo projeto, de um novo sonho de sociedade e mundo a favor das pessoas e classes oprimidas (grifo do autor).

Pelo exposto acima, podemos afirmar que a criticidade freiriana emerge com uma forte conotação sóciopolítica, pois se fundamenta no contexto sócio-histórico educacional brasileiro do período 1960/1970, fortemente marcado pela educação bancária e, assim, pela relação entre opressores e oprimidos.

Traço crítico similar - com igual motivação, conotação e intensidade - é imperceptível nas obras de Morin. No entanto, por não podermos identificá-lo como crítico à semelhança de Freire, não significa que não revele criticidade, de outra forma, em outra medida, com outros recursos. O autor possui uma história de vida marcada por contradições

4. Por polar, aqui, referimo-nos a uma visão que destinge, por exemplo, o certo ou o errado, o bem ou o mal, a razão ou a emoção. Ao apresentar alternativas expressas por meio do conectivo ou, elimina-se a possibilidade de um meio termo. 
pessoais significativas: a morte da mãe, uma doença grave que quase o matou, a ascensão de Hitler ao poder, o rearmamento da Alemanha e a II Guerra Mundial são acontecimentos que deixaram cicatrizes e, naturalmente, provocaram reflexões de várias naturezas.

Em suas obras, notamos que seu espírito crítico pode, por um lado, revelar-se direto e agudo quando, por exemplo, clama por uma reforma do pensamento (MORIN, 1996, 2005) ou propõe uma reforma na educação (MORIN, 2003, 2013). Por outro lado, sua criticidade tende a se amenizar quando apresenta o paradigma tradicional e aponta suas inadequações (MORIN, 2011), ou elenca os sete saberes necessários à educação do futuro (MORIN, 2007). Esses exemplos ilustram um estilo crítico moriniano diferente do estilo freiriano, mas, nem por isso, menos importante ou significativo. Destacamos, no entanto, que Morin embora revele certa dose de criticidade, de forma particular e característica, não se enquadra na arena da Pedagogia Crítica, como Freire - que não apenas nela se insere, mas, principalmente, domina esse espaço epistemológico.

\section{CONSIDERAÇÕES FINAIS}

Articular um diálogo epistemológico entre Freire e Morin, aproximando-os e distanciando-os, e procurando interpretá-los sob a perspectiva transdisciplinar da Linguística Aplicada é, certamente, um desafio que não se cumpre em um artigo. Contudo a introdução a esse desafio nos motiva.

Para vencer a provocação que nos impusemos - ou parte dela -, detalhamos cada autor, separadamente, trazendo aspectos de cada um que nos pareciam relevantes. Depois, procuramos suas conexões e desvios, criando um movimento circular crítico-reflexivo que nos permitiu perceber as ligações de cada um às questões sócio-históricoeducacionais de seu tempo, bem como às perspectivas epistemológicas que cada um abordou no conjunto de sua obra.

Resumidamente, podemos afirmar que ambos se aproximam na medida em que:

- Freire se vê diante de situações de opressão que provocam o silenciamento, e Morin se vê diante do pensamento disjuntivo que separa e impede a religação de saberes. Em ambas as situações, há a necessidade de implementação de uma prática dialógica,

- buscam por um pensamento inovador, em diferentes perspectivas, de acordo com as diferentes épocas e contextos em que viveram ou vivem;

- buscam uma nova visão do homem e do mundo;

- buscam uma nova postura do homem na sociedade;

- entendem que educador e educando são colaboradores no processo ensino-aprendizagem.

Embora se aproximem em alguns aspectos, eles também se distanciam em outros, pois:

- Freire ressalta a conscientização, explorando uma visão crítica que proporciona autonomia e transformação, gerando emancipação. Esse movimento produz um percurso de mão dupla que vai do individual para o social e do social para o individual. Trata-se de uma visão política centrada, pois tem como foco o homem na sociedade: o homem social.

- Morin busca conbecer o conbecimento, para ligar e religar saberes e reformar o pensamento. Com isso, o homem pode atingir uma visão e postura planetárias. Essa é uma visão política, contudo é mais abrangente do que a freiriana, pois tem como foco o homem na Terra e, simultaneamente, a Terra no homem: o homem planetário.

Refletindo sobre o acima exposto, é possível afirmar que os dois autores não se contradizem, não são antagônicos, mas apresentam perspectivas que podem ser entendidas como complementares: seus pontos de vista, veiculados por suas escolhas lexicais, sempre marcadas política e ideologicamente, podem ser estudados de forma complementar para, assim, expandir a compreensão que temos do homem como ser individual, emancipado, social e planetário. 


\section{REFERÊNCIAS}

CELANI, M.A.A. (2017). Linguística Aplicada e transdisciplinaridade. IN: M.M Freire, K.C.N. Brauer e G.Aguilar (orgs.), Vias para a pesquisa: reflexões e mediAÇÕES. São Paulo: Cruzeiro do Sul Educacional. Campus Virtual.

FABRÍCIO, B. F. Linguística Aplicada como espaço de "desaprendizagem": Redescrições em curso. In: MOITA LOPES, L. P. (org.). Por uma linguística aplicada indisciplinar. São Paulo: Parábola Editora, 2006. p. 45 a 65.

FREIRE, P. (1992). Pedagogia da esperança. Rio de Janeiro, Paz e Terra.

FREIRE, P. (2002). Pedagogia da autonomia: saberes necessários à prática educativa. Rio de Janeiro: Paz e Terra.

FREIRE, P. (2005). Pedagogia do oprimido. Rio de Janeiro: Paz e Terra..

FREIRE, P. (2007). Educação e mudança. Rio de Janeiro: Paz e Terra.

GIDDENS, A.; BECK,U. \& LASH, S. (1997) Modernização reflexiva. São Paulo: EdUNESP.

MALACHIAS, M.E.S. \& SILVA, A.C. Reflexões sobre a convergência do pensamento de Paulo Freire e Edgar Morin: contribuições para a formação docente. Cadernos de Educação, FaE/PPGE/UFPel, no.42, p. 223-242, 2012.

MOITA LOPES, L.P. (org.). (2006) Por uma linguística aplicada INdisciplinar. São Paulo: Parábola Editorial.

MORAES, M. C. (2007). A formação do educador a partir da complexidade e da transdisciplinaridade. Diálogo Educacional, v.7, n.22, p.13-38.

MOREIRA, C. E. Criticidade. (2016) In: D.R. Streck; E.Redin; J.J.Zitkoski (orgs.), Dicionário Paulo Freire. $3^{\text {a }}$. edição. Belo Horizonte: Autêntica Editora.

MORIN, E. (1990). O método IV. As idéias: a sua natureza, vida, babitat e organização. Portugal: Publicações Europa-América.

MORIN, E. (1996). O problema epistemológico da complexidade. Lisboa: Europa- -América.

MORIN, E. (2002). A religação dos saberes: o desafio do século XXI. São Paulo, Bertrand Brasil.

MORIN, E. (2003). Cabeça bem-feita: repensar a reforma, reformar o pensamento. Tradução de Eloá Jacobina. 8 a ed. Rio de Janeiro: Bertrand Brasil.

MORIN, E. (2005). Ciência com consciência. Tradução de Maria D. Alexandre e Maria Alice Sampaio Dória. $8^{a}$. edição. Rio de Janeiro: Bertrand Brasil.

MORIN, E. (2007) Os sete saberes necessários à educação do futuro. São Paulo: Cortez. UNESCO.

MORIN, E. (2011). Introdução ao pensamento complexo. Tradução Eliane Lisboa. $4^{\mathrm{a}}$ ed. Porto Alegre: Sulina.

MORIN, E. (2013) A via para o futuro da bumanidade. Tradução: Edgard de Assis Carvalho e Mariza Perassi Bosco. Rio de Janeiro: Bertrand Brasil.

PORTELLA, E. (1993) Disciplina complexa. Revista Tempo Brasileiro, n.113, p.5-8, abril-junho.

SANTOS, A. A. (2018). Paulo Freire e sua trajetória rumo à concepção do ato pedagógico como ação dialógica. IN: K.L.V.Lira (org.), As diferentes faces e interfaces de uma educação para o século XXI: diálogos fronteiriços com Paulo Freire, Edgar Morin, Fernando Hernández, Pierre Lévy e Rudolf Steiner. $1^{\text {a }}$. Edição. Kindle. Curitiba: Appris.

SCHEIFER, C. L. (2013). Transdisciplinaridade na Linguística Aplicada: um processo de desreterritorialização - um movimento do terceiro espaço. Revista Brasileira de Linguística Aplicada, v.13, n.3, p. 919-939. 
SCHOLZE, N.T \& SCHOLZE, M.L. Morin e Freire: um diálogo possível na educação. Revista Acadêmica Licencia\&acturas*Ivoti* v.2, no.1, p.67-74, 2014.

VENN, C. (2000). Occidentalism. Modernity and subjectivity. London: Sage.

Recebido: 1/2/2020

Aceito: 5/3/2021

Publicado: 8/3/2021 